\title{
Marc Dambre et Bruno Blanckeman (éds), Romanciers minimalistes 1979-2003
}

\section{Anna Bucarelli}

\section{(2) OpenEdition}

1 Journals

\section{Edizione digitale}

URL: http://journals.openedition.org/studifrancesi/629

DOI: 10.4000/studifrancesi.629

ISSN: 2421-5856

\section{Editore}

Rosenberg \& Sellier

\section{Edizione cartacea}

Data di pubblicazione: 1 aprile 2015

Paginazione: 197-198

ISSN: 0039-2944

\section{Notizia bibliografica digitale}

Anna Bucarelli, « Marc Dambre et Bruno Blanckeman (éds), Romanciers minimalistes 1979-2003 », Studi Francesi [Online], 175 (LIX | I) | 2015, online dal 01 avril 2015, consultato il 18 septembre 2020. URL http://journals.openedition.org/studifrancesi/629 ; DOI : https://doi.org/10.4000/studifrancesi.629

Questo documento è stato generato automaticamente il 18 settembre 2020.

\section{(c) (i) $\odot$}

Studi Francesi è distribuita con Licenza Creative Commons Attribuzione - Non commerciale - Non opere derivate 4.0 Internazionale. 


\title{
Marc Dambre et Bruno Blanckeman (éds), Romanciers minimalistes 1979-2003
}

\author{
Anna Bucarelli
}

\section{NOTIZIA}

Romanciers minimalistes 1979-2003, Paris, Presses Sorbonne Nouvelle, 2012, pp. 362.

1 Il volume raccoglie a distanza di quasi un decennio i contributi presentati al Colloque di Cerisy con un breve «Avant-propos» dei curatori (pp. 7-12) che, nel collocare il progetto originario nel suo contesto, riconoscono nel décalage della pubblicazione la possibilità di cogliere nello stesso tempo «un moment de l'histoire littéraire et l'espace parcouru, les renouvellements des œuvres comme leurs cohérences et leurs continuités» (p. 7). Dei romanciers minimalistes attivi tra il 1979 e il 2003 si analizza in particolare l'opera di Éric Chevillard (Jacques POIRIER, De la littérature et autres bagatelles: sur Éric Chevillard, pp. 15-26; David RUFFEL, Les romans d'Éric Chevillard sont très utiles, pp. 27-32; Marie-Odile ANDRÉ, Récit contrarié, récit parodique: la figure auctoriale chez Chevillard, pp. 33-42; Anne COUSSEAU, Lecture, jeu et autobiographie dans "Du hérisson" d'Éric Chevillard, pp. 231-243; Jean-Louis HIPPOLYTE, L'anti-biographe, ou les absences de Chevillard, pp. 245-253), Jean Echenoz (Sophie DERAMOND, Minimalisme et spatialité chez Jean Echenoz, pp. 93-101; Mirjam TAUTZ, Jean Echenoz en Allemagne: édition et réception, pp. 113-124; Christine JÉRUSALEM, Identification d'une femme: les portraits féminins dans l'œuvre de Jean Echenoz, pp. 165-176; Isabelle DANGY, Suspension, détachement, apesanteur dans les romans de Jean Echenoz, pp. 177-185; Johan FAERBER, "Nous trois": Jean Echenoz ou la généalogie d'une dialectique, pp. 187-193; Van KELLY, Tentation du minimalisme et puissance du bricolage: Jean Echenoz vs Agnès Varda, pp. 271-281; Wolfgang ASHOLT, "Dense avec légèreté" ou "Au piano" de la fiction, pp. 283-293) e Jean-Philippe Toussaint (Gianfranco RUBINO, Jean-Philippe Toussaint: une narrativité paradoxale, pp. 71-80; Laurent DEMOULIN, La fougère dans le frigo, pp. 81-92; 
Philippe CLAUDEL, Faire (ou défaire) l'amour: géographie de l'éros dépité, pp. 127-139; Bruno BLANCKEMAN, "Faire l'amour" à la Toussaint (sur quelques postures littéraires minimalistes), pp. 141-153), cui si aggiungono Patrick Deville (Pierre HYPPoLITE, Hyperréalisme et représentation minimaliste dans "La Femme parfaite" de Patrick Deville, pp. 55-69), Emmanuèle Bernheim (Marc DAMBRE, Emmanuèle Bernheim: un minimalisme hors Minuit?, pp. 103-112), François Bon (Mathilde BARRABAND, La minutie de François Bon. Une tentative d'épuisement de l'espace urbain, pp. 195-204), Hélène Lenoir (Stéphane BIKIALO, Hélène Lenoir: un minimalisme orchestré, pp. 255-269) e pochi altri autori secondo un approccio comparativo (Pascal mougin, Réalités contemporaines chez Echenoz, Toussaint, Oster: une tentation problématique, pp. 205-215; Ullrich LANGER, Esthétique de la gêne chez Toussaint, Gailly et Oster, pp. 217-227; Aline MURA-BRUNEL, "Retour en grâce" de la fiction: "Un soir au club" de Christian Gailly et "Faire l'amour" de Jean-Philippe Toussaint, pp. 295-307; Olivier BESSARD-BANQUY, La relation amoureuse chez les "jeunes auteurs de Minuit", pp. 155-165; Lionel RUFFEL, Le minimal et le maximal ou le renouvellement, pp. 43-54).

2 Articolato in tre principali ambiti di ricerca, il discorso critico affronta il corpus di opere dal punto di vista della storia letteraria (il retour aux normes del récit, le filiazioni e relazioni con altri linguaggi artistici), della cultura e antropologia della modernità (in particolare, attraverso la rappresentazione della relazione sentimentale e la visione del mondo contemporaneo), nonché dal punto di vista etico ed estetico (il rapporto con le ideologie e la Storia, la concezione del romanzo e le strategie narrative). Secondo i curatori, il dibattito sulla controversa nozione di minimalismo al centro del volume fa emergere il definitivo tramonto degli -ismi con le loro categorie estetiche e mostra come la molteplicità e diversità dei criteri con cui ci si propone di definire un roman minimaliste (criteri esogeni come la ricezione, l'appartenenza alla nuova generazione Minuit, la situazione culturale della letteratura con la perdita di prestigio sociale dello scrittore, e la dimensione genealogica; e criteri endogeni come la poetica narrativa della frattura e dei blancs, il non-dit, il cliché, il registro ludico, l'indecidibilità del senso), «loin de lester la notion d'une densité conceptuelle, en font flotter la signification même»: irriducibili a una categoria letteraria, tali criteri aiuterebbero piuttosto a «penser les mutations de la fiction romanesque au tournant du xxI ${ }^{\mathrm{e}}$ siècle» (p. 11). In definitiva, il controsenso di una "systématisation de la démarche minimale sous forme de catégorie» spiegherebbe «la faillite conceptuelle du minimalisme» (p. 12). Completano il volume la trascrizione del dialogo-intervista con Patrick Deville (Entretien con Patrick Deville "Plus formaliste peut-être que minimaliste...", pp. 311-333), una mise à jour bibliografica (pp. 333-340) e l'indice dei nomi (pp. 341-348). 